16 a 18 de outubro de 2019 - Campinas | Brasil

\title{
Evaluation of the energetic profile of patients with odontalgias
}

\section{Ariadne Lopes Ferreira*, Talita Bonato de Almeida, Maria da Luz Rosário de Sousa.}

\section{Abstract}

The aim of this study was to evaluate the energetic levels of patients with toothache before and after a therapeutic intervention (acupuncture or dipyrone analgesic) to relieve this pain. The results showed a reduction in energy after interventions in all study groups - acupuncture group, placebo-acupuncture group, dipyrone group and placebo-dipyrone group - being significant only in placebo-acupuncture group.

\section{Key words:}

Acupuncture, Therapy, Pulpitis.

\section{Introduction}

The aim of this study was to evaluate the energetic levels of patients with toothache before and after a therapeutic intervention (acupuncture or dipyrone analgesic) to relieve this pain.

\section{Method}

The data were from a clinical trial, which included 56 volunteers in 4 groups: acupuncture group (GA) placebo-acupuncture group (GPA) dipyrone group (GD) placebo-dipyrone group (GPD)

Inclusion criteria: odontalgia of pulpar origin with Visual Analogue Scale (VAS) above 4 and absence of medication for this pain in the last 12 hours.

Before and after the therapeutic intervention of each group, the volunteers had their energy level measured by the Ryodoraku method.

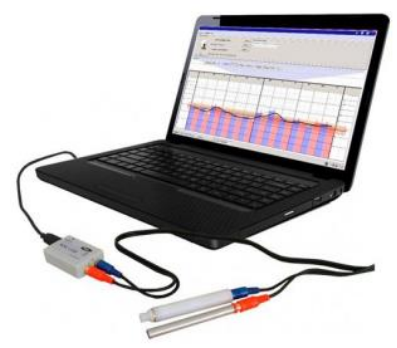

Image 1. Ryodoraku.

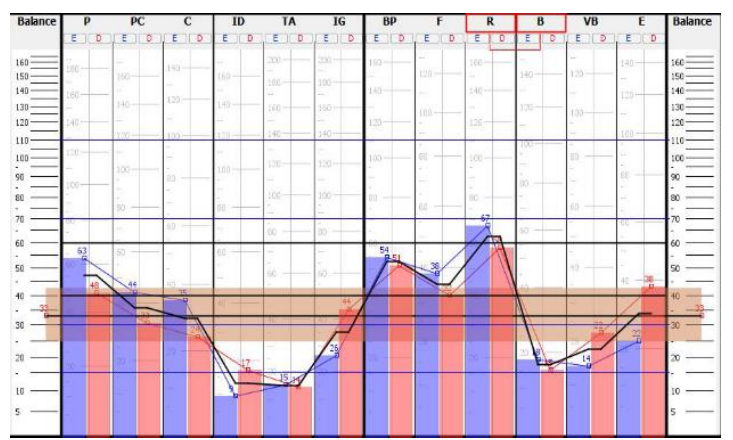

Image 2. Energetic profile within the normal rage.

The data obtained were statistically analyzed in the BioStat program, using paired t-tests and ANOVA, adopting $\mathrm{p} \leq 0.05$.

\section{Results and Discussion}

All the volunteers presented energetic profile below the normal range before the therapeutic interventions.

The means and standard energy deviations before and after the interventions per group were GA: $10.714 \pm 4.268$ and $9.643 \pm 4.814(p<0.119) ;$ GPA: $15,643 \pm 7,448$ and $13,214 \pm 8,135(p<0.007) ; G D: 12,714 \pm 6,069$ and 11,071 $\pm 5,902$ ( $p<0.112)$; GPD: $11,571 \pm 3,857$ and 10,500 \pm $5,273(p<0.263)$, respectively.

The results showed a reduction in energy after interventions in all study groups, being significant only in GPA.

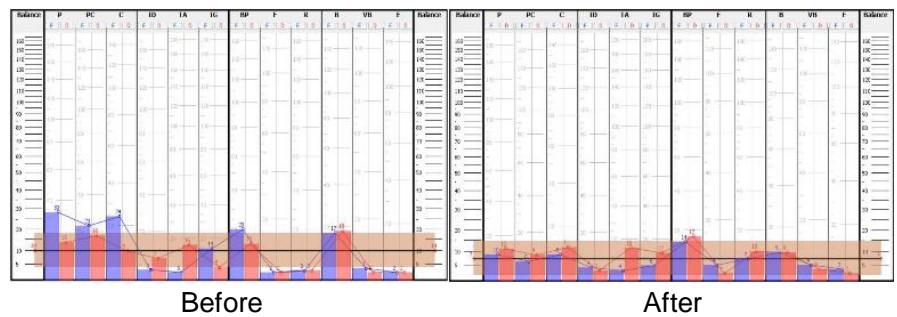

Image 3. Energetic profile before and after therapeutic intervention.

\section{Conclusions}

There was a reduction of energy in the sham acupuncture group, which corroborates with data from the literature on possible effects of placebo acupuncture.

\section{Acknowledgement}

\section{DAAPESP 2018/26603-7}

Boleta-Ceranto DCF, Alves T, Alende FL. O efeito da acupuntura no controle da dor na odontologia. Arq. Ciênc. Saúde Unipar 2008; 12(2):143-148.

Zotelli VLR, Grillo CM, Gil MLB, Wada RS, Sato JE, Sousa MLR. Acupuncture Effect on Pain, Mouth Opening Limitation and on the Energy Meridians in Patients with Temporomandibular Dysfunction: A Randomized Controlled Trial. J Acupunct Meridian Stud 2017;10(5):351e35.

Nakatani Y, Yamashita K. Ryodoraku Acupuncture. A guide for application of ryodoraku therapy electrical acupuncture, a new autonomic nerve regulating therapy. Tokyo ed. Ryodoraku Research Institute. 1977.

Andrade ED. Terapêutica Medicamentosa em Odontologia: Procedimentos clínicos e uso de medicamentos nas principais situações da prática odontológica. São Paulo: Artes Médicas, 2006. 216 p. $2^{\mathrm{a}}$ edição. 